\title{
We welcome a new Editor as we say farewell to Professor Mayo
}

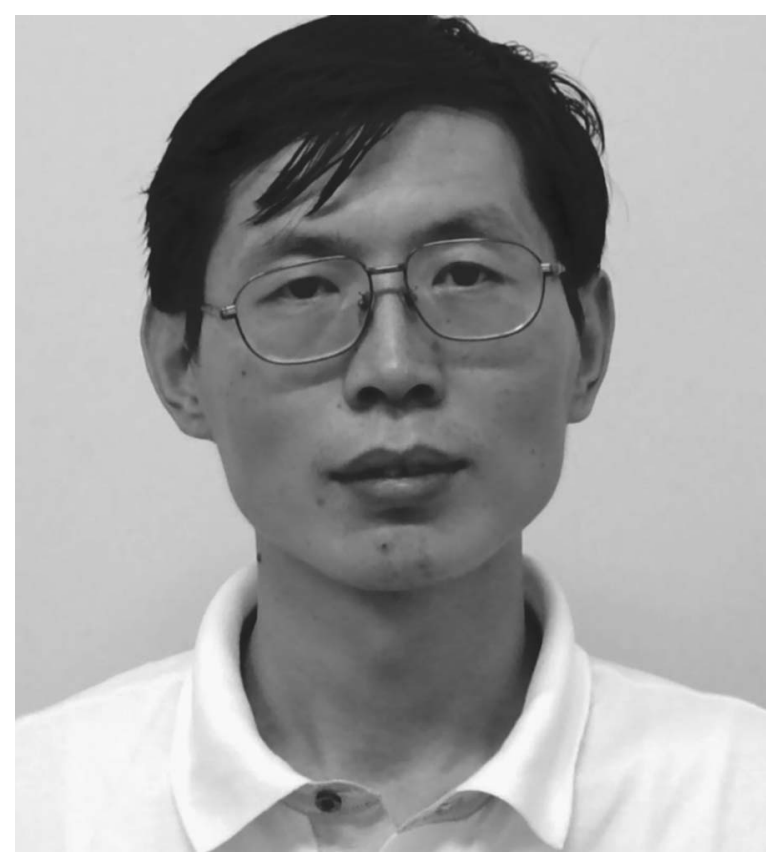

We are delighted that Professor Xiaolong Chen (pictured above) has accepted our invitation to serve as an editor for Powder Diffraction. Professor Chen received his Ph.D degree and subsequently joined the Institute of Physics, Chinese Academy of Sciences in 1991. In the mid-1990s he was an Alexander von Humboldt fellow at Heidelberg University and Bayreuth University in Germany. Dr. Chen's main research area covers the synthesis of new compounds, crystal growth, and structural and physical characterization of inorganic functional materials using various methods including powder X-ray diffraction. He authored and co-authored over 200 papers in international peer-reviewed journals and coauthored the monograph, "Phase relations and crystal structures of high Tc oxide superconductors." He is head of the research group on new materials exploration and crystal growth at the Institute of Physics, vice chairman of the Chinese Society of Crystallography, an active member of ICDD, and a regional co-chairman of the ICDD Technical Committee. He has been the principal investigator of many ICDD Grant-in-Aid projects since 2000.

Professor Chen, among others, organized and he served as executive secretary of the 9th Chinese National X-ray Diffraction Conference and ICDD Workshop held October 1421, 2006 in Hangzhou, China. I had the opportunity to attend the conference and was very impressed with the program. I also found that the Chinese diffraction community is represented by energetic and highly motivated scientists and researchers. X-ray diffraction technology in China is making rapid advances and may reach the world level quickly, if it has not already. With Professor Chen as an editor, we hope this will encourage Chinese scientists to submit their research results to Powder Diffraction. As a result, Powder Diffraction can serve as a window between XRD scientists in China and the rest of the world.

I would like to thank Professor William E. Mayo for his services as a new diffraction data editor for the past ten years. Because of health reasons, he has resigned as editor. We wish him the best, and appreciate all the years of hard work he has done for Powder Diffraction.

Powder Diffraction has editors located around the world including Professor Norberto Masciocchi in Italy, Professor Brian H. O'Connor in Australia, Dr. Hideo Toraya in Japan, Dr. José Miguel Delgado in Venezuela, and Professor Xiaolong Chen in China. Authors are urged to submit their technical papers to the editor closest to them or to the editor most suitable to the subjects of their papers. Papers on new diffraction data should be submitted directly to Frank McClune or to me.

As a service to the crystallography community, Powder Diffraction has launched a new section on crystallography education last year. This section intends to provide tutorial and instructional articles related to powder diffraction crystallography. We wish to foster creation of educational materials covering topics not found in books or manuals. Furthermore, a new range of computer-assisted technologies is advancing the methods available for instruction, and we hope to see articles about teaching methods using both traditional media (journal pages) and new media (web pages, streamingvideo, and more). Two excellent articles were published in this section last year: " $R$ factors in Rietveld analysis: How 
good is good enough?" by Brian H. Toby and "Magnetic structure refinement with neutron powder diffraction data using GSAS: A tutorial" by J. Cui, Q. Huang, and Brian H. Toby. Two more articles appear in this issue: "Chemical reasonableness in Rietveld analysis; organics" by James Kaduk and "A new approach for instruction in powder crystallography" by Brian H. Toby. Researchers and students working in crystallography and powder diffraction should find these articles very useful. The section on crystallography education will publish invited and contributed articles. Authors are encouraged to discuss their ideas in advance of manuscript completion with one of our crystallography education editors, James Kaduk or Brian H. Toby. Contact information can be found in the masthead.
Ting C. Huang Editor-in-Chief 